\title{
Article
}

\section{Design of Unimorph Type 3DOF Ultrasonic Motor}

\author{
Vytautas Jūrènas ${ }^{1}$, Gražvydas Kazokaitis ${ }^{1, *}$ and Dalius Mažeika ${ }^{2}$ \\ 1 Institute of Mechatronics, Faculty of Mechanical Engineering and Design, Kaunas University of Technology, \\ Studentu str. 56, 51424 Kaunas, Lithuania; vytautas.jurenas@ktu.lt \\ 2 Department of Information Systems, Faculty of Fundamental Sciences, Vilnius Gediminas Technical \\ University, Sauletekio av. 11, 10223 Vilnius, Lithuania; dalius.mazeika@vgtu.lt \\ * Correspondence: grazvydas.kazokaitis@ktu.edu; Tel.: +37-067-220-243
}

Received: 15 July 2020; Accepted: 10 August 2020; Published: 13 August 2020

\begin{abstract}
A new design of 3 degrees of freedom (DOF) piezoelectric ultrasonic motor (USM) is introduced in this paper. The concept of this design is to incorporate a spherical rotor between two piezoelectric transducers. Each transducer is coupled with a flange, and it operates like a unimorph structure. Such a design of the transducer allows to increase the amplitude of the vibrations and to generate the higher torque and driving force used to achieve 3DOF rotary motion of the spherical rotor. The proposed USM may be used for humanoid robots, optomechanical systems, or small satellites. This USM consists of several components, is lightweight and reliable. Numerical analysis and experimental studies were performed to validate the feasibility of this drive, to find out proper resonant frequencies for the unimorph, and optimize the shape of the flange. Experimental studies were accomplished to validate the results of the numerical analysis and to validate the operating principles of the piezoelectric motor.
\end{abstract}

Keywords: piezoelectric actuator; 3DOF actuator; spherical rotor; ultrasonic motor; unimorph; FEM; piezoelectric transducer; piezoelectric drive; precise rotation

\section{Introduction}

Nowadays, piezoelectric devices are very common in a wide range commercial and industrial areas. Piezoelectric devices are used in optomechanical systems, micromanipulators, and robotics $[1,2]$. Typically, piezoelectric actuators are of small size, simple design, and generate micrometer-scale mechanical displacement (from $0.5 \mu \mathrm{m}$ to $150 \mu \mathrm{m}$ ). Because of the small size and mass, the inertia force of the device is low, and therefore, the response time is short. These features of the piezoelectric actuator allow to achieve good performance and power/volume ratio. It is worth mentioning that the piezoelectric actuator is made from non-magnetic materials and can be used where strong magnetic fields are undesirable to any equipment and should be protected from the additional magnetic noise. Piezoelectric actuators are able to reach extremely high precision with micro- or even nano-resolution and are driven at high-frequency modes that can generate unlimited linear or rotary motion. These features allow to integrate them into a wide variety of applications.

Simple design and uncomplicated working principles allow using piezoelectric devices in industries such as space, satellite communication, and navigation. Specifications for the devices which may be used for space application are rigorous, i.e., small mass and volume, easy integration, and high reliability are only a few of those requirements. Piezoelectric actuators and devices are good candidates for such tasks and may be used for space applications.

However, the majority of piezoelectric actuators and motors are the single degree of freedom (DOF) devices, while there are many applications where several DOF systems are required. Those systems can be assembled using several actuators, but the systems become complicated, and it is challenging to manage errors while combining several single DOF actuators. Moreover, such behavior is not 
acceptable for the tasks, where the size and weight of the mechanism are limited, and high precision becomes an issue. Oppositely, building a large system requires separate units because of the size limitations of piezoelectric actuators [3]. However, in this approach, the size of the motor must be designed in a way when a minimum number of elements are needed.

Multi-DOF ultrasonic motors are devices that can set orientation and positioning of the object in any direction. 3DOF piezoelectric actuator, which consists a cylindrical stator and the round-shaped rotor, was designed and developed by Zhao et al. This actuator actuates the longitudinal and bending vibrations when the harmonic driven signal is applied to the piezoelectric rings [4]. Hassani et al. [5] designed and investigated a novel pyramidal-shaped three DOF positioning mechanism. This mechanism is made from aluminum alloy, and three piezoelectric actuators are inserted at every $120^{\circ}$ angle. Such a mechanism can deliver 3D elliptical movements of the contacting points in space. There are more studies on the investigation of ultrasonic motor (USM) capability to generate a rotational movement of the spherical rotor. Analytical studies of linear piezoelectric unimorph model were described by Smith et al. Wang and Cross modified and improved this analytical model. Lim et al. proposed 3D electromechanical analysis of a piezoelectric unimorph [6].

Vasiljev et.al. proposed a new design of 3DOF piezoelectric actuator developed to rotate the spherical rotor about three axes [7]. The rotor is placed on the square shape vibrating frame that is excited by four piezostacks. The elliptical motion of four driving tips is transferred to the rotation of the rotor. The rotation direction of the rotor is controlled by changing the amplitude and phase of the harmonic electric signal of the different piezo stacks.

Li et.al. proposed 3D hybrid piezo electrical drive with spherical rotor which is made using permanent magnetic semi-spheres [8]. These semi-spheres are hollow and connected together. This sphere is the rotor of the drive. In between the sphere are three piezoelectric disks at $120^{\circ}$. Piezoelectric disks are always in a contact with the inner side of the sphere. When harmonic electric signal is applied for the piezoelectric actuators, running wave is generated and the sphere is rotated. This drive is complex and has many peripheral parts.

Keller et.al proposed 3DOF spherical drive with piezoelectric rotor [9]. This drive has spherical rotor which is made using piezoelectric material. Electrodes are located on the inner and outer faces of the sphere. This rotor is inserted in a thick aluminum flange, which is the stator of the drive. When an electric driven signal is applied, the sphere deforms into 3D shapes and rotates the sphere. This sphere can rotate around three axes, but the angles are limited.

Lu et.al proposed 3DOF spherical drive with two stators [10]. These stators are made using four legs which acts like a springs and piezoelectric disk-type transducer. The sphere is compressed between two stators. Those legs also are used for pre-load of the sphere. The drive is compact, but heavy: stators are made using thick metal flanges, four legs are thin and may not keep long time due fatigue.

This paper presents an innovative design concept of 3DOF USM with two ring-shaped piezoelectric transducers. Each piezoelectric transducer is glued on a thin elastic flange and forms a unimorph type actuator which can be excited at higher vibration modes for generation of 3DOF rotary motion of the spherical rotor. Numerical and experimental studies were performed and presented in this paper. This is a continuous research of 3DOF drive that was investigated and published in a previous article [11]. The aim of this work is to improve accuracy and remove supplementary components from the design.

For the comparison, Table 1 was added which highlights the differences between proposed USM motor and others mentioned in a paper. 
Table 1. Comparison of the parameters of reviewed and proposed motors.

\begin{tabular}{ccccc}
\hline Authors & Operation Frequency [kHz] & Excitation Voltage $\left(\mathbf{V}_{\mathbf{p}-\mathbf{p}}\right)$ & Rotation Speed $(\mathbf{R P M})$ & Size of the Motor [mm] \\
\hline Bansevicius and et al. [4] & 93.6 & 40 & $4.05 \times 10^{-4}$ & $33 \times 20$ \\
Hassani and et al. [5] & $0.05-1.184$ & 100 & - & $\sim 100 \times \sim 120 \times \sim 60$ \\
Chattaraj and et al. [6] & - & - & 100 & $35 \times 7 \times 5$ \\
Li and et al. [8] & $\sim 41$ & 200 & 32 & - \\
Keller and et al. [9] & 54 & 120 & - & $\mathrm{R}=12$ \\
Lu and et al. [10] & 57.3 & $40 / 60$ & $27 / 30$ & $36 \times 28$ \\
Proposed motor & $92.48 / 93.72$ & 50 & & - \\
\hline
\end{tabular}

\section{Design and Working Principles}

The proposed piezoelectric USM consists of two ring-shaped piezoelectric transducers glued on the thin metal flanges that have disc shape (Figure 1). The spherical rotor is placed in between piezoelectric transducers. Transducers are driven by a harmonic electric signal with the frequency of higher vibration modes of the unimorph structure. The stator of the USM is a composite structure, in which the flanges and piezoelectric transducers are bonded using epoxy resin and are forming two unimorph piezoelectric actuators. This type of actuators has the benefit of generating larger flexural displacements with higher mechanical force and torque, which rotates a sphere. The proposed USM potentially can be used in optomechanical systems, humanoid robotics, military, and space applications [12].

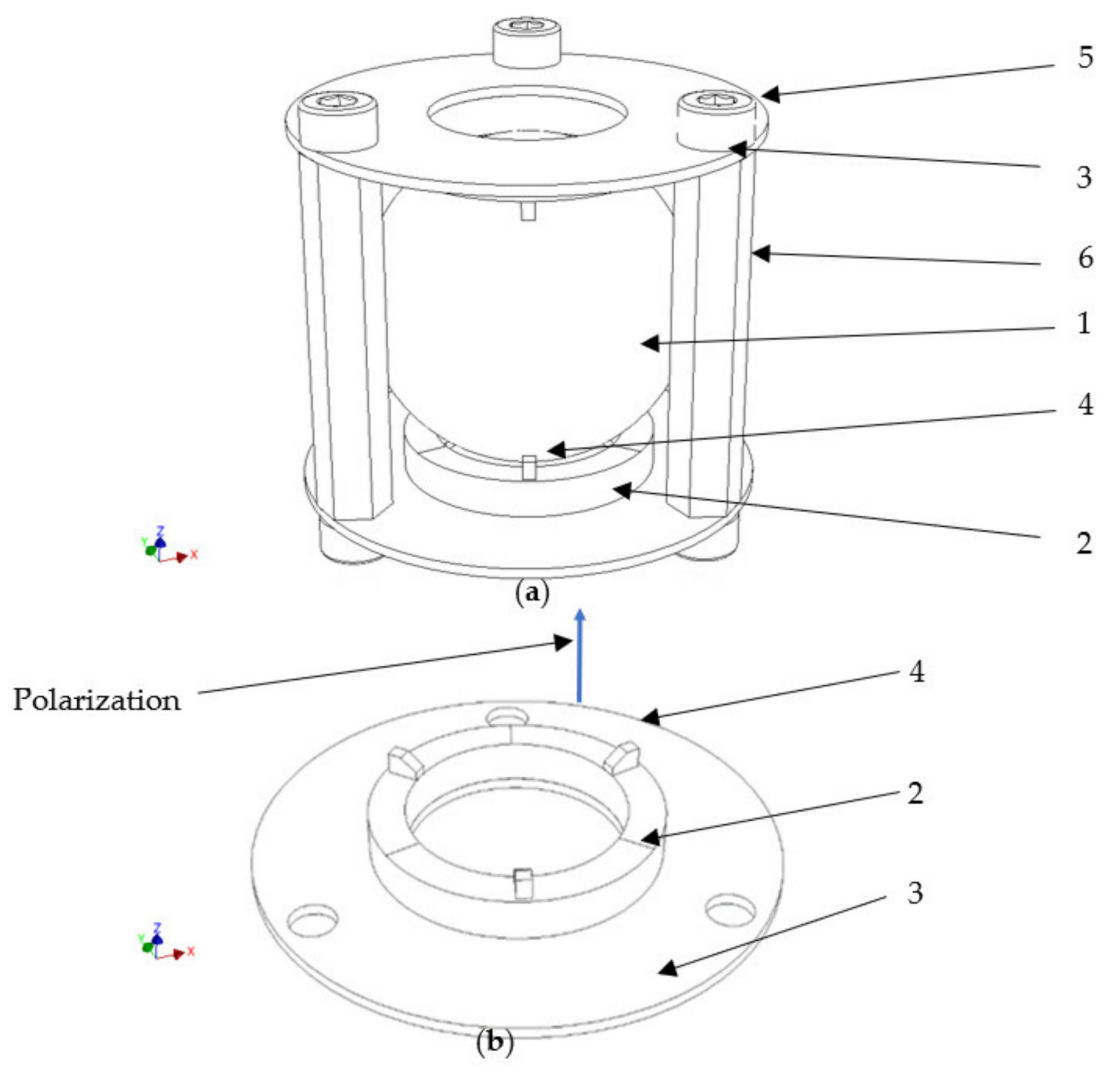

Figure 1. Cont. 


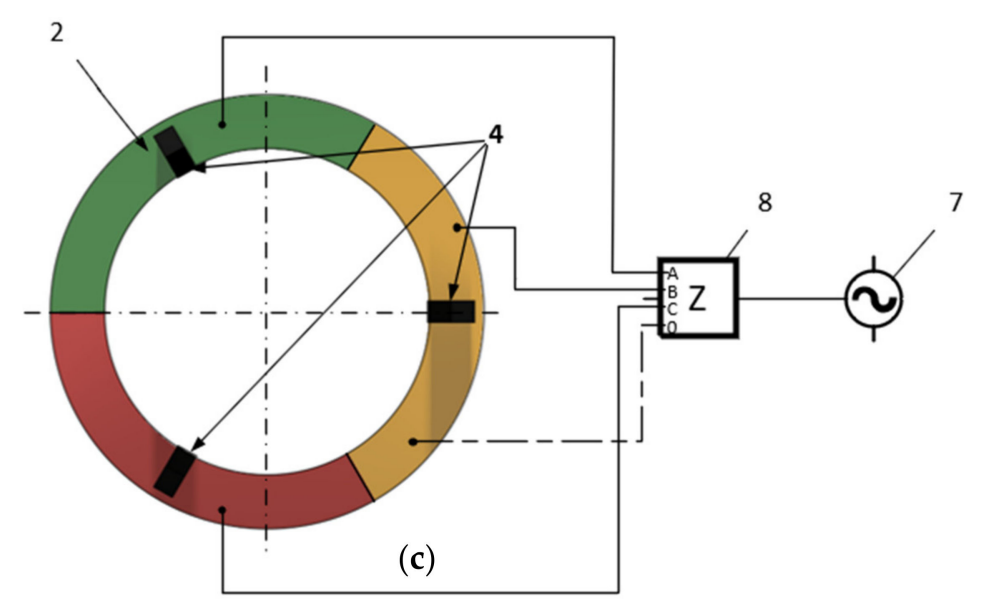

Figure 1. Structure of the piezoelectric 3 degrees of freedom (DOF) rotary ultrasonic motor (USM) with a spherical rotor (a); view of the piezoelectric unimorph actuator (b) and schematic representation of the USM drive and layout of segmented electrodes of the piezoelectric transducer (c): 1-spherical rotor; 2-piezoelectric transducer; 3-flange; 4-contact element; 5-nut; 6-bolt; 7-signal generator; 8-controller.

The basic design idea and structure of the developed USM is presented in Figure 1a. A spherical rotor (1) is inserted among two unimorph piezoelectric actuators, as presented in Figure 1b. The motor is symmetrical; therefore, the top and bottom actuators are identical. Piezoelectric ring-shaped transducers are made from hard type PZT- 4 ceramics. The piezoceramic rings were polarized in the thickness direction, parallel with $Z$ axis, and electrodes cover the upper and lower surfaces of the piezoelectric transducer. Electrodes on the upper surface are partitioned in 3 sections with an angle of $120^{\circ}$ between them. The electrode on the bottom surface is continuous and glued on the flange. Three contact elements (4) are glued on the upper electrode (2) and they are located in the center of each segmented electrode.

When the electric signal makes the piezoelectric transducer vibrate, then the frictional force acting between the contact element and the spherical rotor is generated, and the rotation of the rotor is obtained. Three bolts $(5,6)$ are used to get the motor assembled. The preload force between contact elements (4) and spherical rotor (1) can be adjusted by turning the nuts (5).

The USM driving scheme and layout of segmented electrodes of the piezoelectric transducer are shown in Figure 1c. The setup consists of a three-channel signal generator (7) and controller (8). Three pairs of segmented electrodes of the upper and lower transducers are electrically connected to channels A, B, C. The harmonic electric signal is amplified by controller. Only one channel is active at a certain moment and it is used to rotate the sphere. Such setup allows achieving excitation of a specific segment of the piezoelectric actuator and induce movements in elliptical trajectories of the contact element (4).

The operating principle of the proposed USM is provided by the elliptical motion of the excited contact elements (Figure 1b) when a higher bending mode of the actuator appears. While the driven electric signal is defined at particular frequency and applied for specific electrodes of piezoelectric actuator, the resonant vibrations are excited. Accordingly, the elliptical motion of the contact elements is obtained, and an oblique impact on the surface of the sphere is accomplished. As a result, the directional rotation of the rotor around one particular axis is generated. The rotation speed and torque of the rotor are controlled by the amplitude of the electric signal. The direction of rotation is changed by switching channels of the signal generator and by exiting the particular pair of the segmented electrodes.

\section{Numerical Modeling of the Actuator}

The 3D simplified model of the unimorph actuator was designed, and numerical simulations were executed. The aim of the simulations was to determine resonant frequencies and vibration modes using 
three different designs of actuator's flange. Numerical modeling was performed when the piezoelectric actuator was analyzed as unimorph structure, i.e., a transducer and flange were bonded using epoxy resin, and the other piezoelectric transducer was fixed on the flange using soft rubber spacers. The 3D vibration amplitudes and trajectories of contact points of the actuator were analyzed. All simulations were performed in two steps: firstly, modal analysis was executed, and then, harmonic response studies were performed.

USM actuator consists of a piezoelectric ring-shaped transducer, contact elements, and thin flange. All geometry was designed and prepared using Autodesk Inventor Professional 2018, and COMSOL Multiphysics 5.4 was utilized for the calculations. Preparing models for calculations, only specific components were designed i.e., piezoelectric transducer, contact elements, and thin flange. Other components such as the glue layer, soft rubber spacer, and electrodes, were not included. Piezoelectric ring-shaped transducer dimensions were as follows: outside diameter was $20 \mathrm{~mm}$, inside diameter was $15 \mathrm{~mm}$, and the thickness was $3 \mathrm{~mm}$. PZT-4 hard type piezoceramics was used for the production of piezoelectric transducer. This piezoceramics is widely used for the USM motors [13-15].

The disc and triangle-shaped flange were investigated. The thin flanges were made from phosphor bronze C52100 and had the following dimensions: outer diameter was $35 \mathrm{~mm}$, central hole was $15 \mathrm{~mm}$, and thickness was $0.3 \mathrm{~mm}$. Dimensions of the actuators and flanges are presented in Figure 2. Contact elements are made from friction-resistant material-Aluminum oxide $\left(\mathrm{Al}_{2} \mathrm{O}_{3}\right)$. Dimensions of these contact elements were as follows, i.e., width: $1 \mathrm{~mm}$; length: $2.2 \mathrm{~mm}$, and height: $1.5 \mathrm{~mm}$. The properties of used PZT-4 piezoceramic and dimensions of components are presented in Table $2[11,16-20]$.

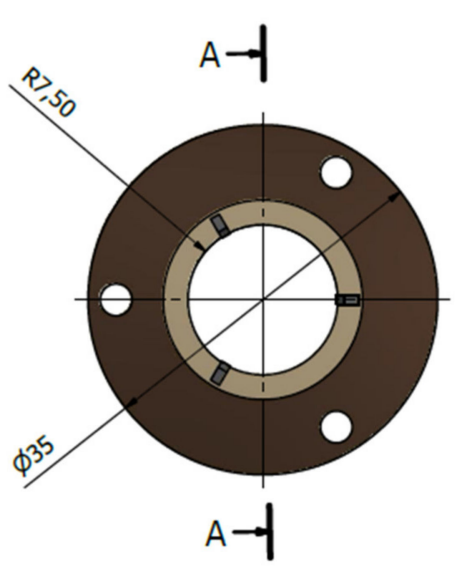

(a)

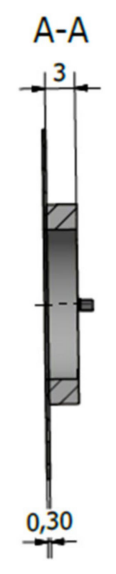

A-A

Figure 2. Dimensions of actuators and flanges: (a) actuator with disk-shaped flange; (b) actuator with triangle-shaped flange.

Table 2. Dimensions and material properties of the actuator.

\begin{tabular}{|c|c|c|c|c|}
\hline Property & Unit & Transducer & Flange & Contact Element \\
\hline Material & & PZT-4 & Phosphor Bronze C52100 & Aluminum oxide $\left(\mathrm{Al}_{2} \mathrm{O}_{3}\right)$. \\
\hline Density & $\mathrm{kg} / \mathrm{m}^{3}$ & 7500 & 8800 & 3950 \\
\hline Dimensions & $\mathrm{mm}$ & OD-20; ID-15; T-3 & OD-35; ID-34; T-0.3. & $\mathrm{W}-1 ; \mathrm{L}-2.2 ; \mathrm{H}-1.5$ \\
\hline Young Modulus & GPa & 63 & 110 & 215 \\
\hline Dielectric permittivity, $10^{3}$ & $\mathrm{~F} / \mathrm{m}$ & $\varepsilon_{11}=1.48, \varepsilon_{22}=1.48, \varepsilon_{33}=1.3$ & - & - \\
\hline Piezoelectric coupling matrix, $10^{-12}$ & $\mathrm{C} / \mathrm{N}$ & $\begin{array}{c}d_{31}=-123, d_{32}=-123, d_{33}=289, d_{24}=496 \\
d_{15}=496\end{array}$ & - & - \\
\hline
\end{tabular}


Modal-frequency analysis was accomplished while the actuator was not clamped, and short circuit boundary condition was applied. Piezoelectric transducer and assembled unimorph actuator with two types of the flanges were analyzed (Figure 3). The aim of this study was to find out the modal shapes and natural frequencies of the actuator that can be used for rotor driving. Trajectories of the displacements were investigated, these trajectories are on the top contact element, shown in Figure 4.

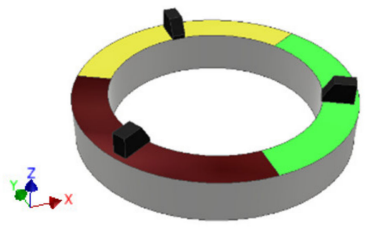

(a)

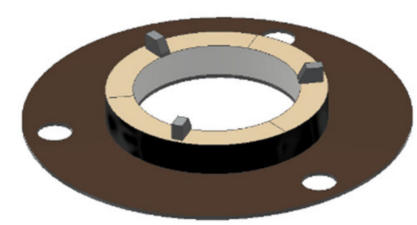

(b)

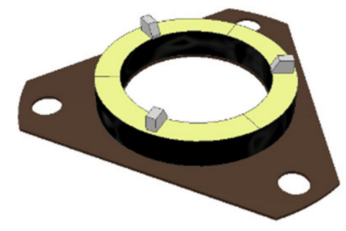

(c)

Figure 3. Numerical models which were used for simulations: (a) piezoelectric actuator, when flange is bonded using soft rubber spacers; (b) piezoelectric unimorph with ring-shaped flange; (c) piezoelectric unimorph with triangle-shaped flange.

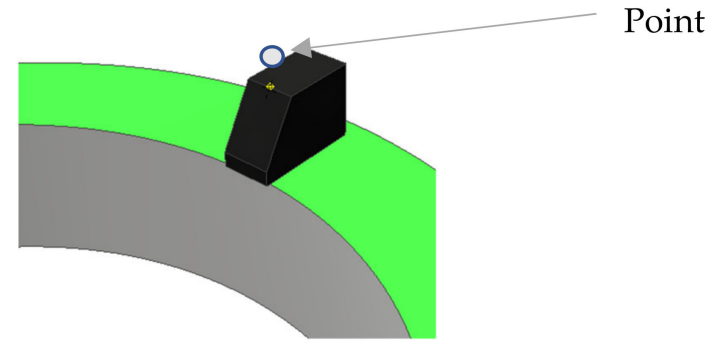

Figure 4. A point on contact element which was used for trajectory calculations.

Firstly, a modal-frequency analysis of the piezoelectric transducer was performed. Frequency range from 20 to $110 \mathrm{kHz}$ was studied. Results showed that several modes had dominating displacements in axial and radial directions of the ring-shaped transducer. Such type displacements are needed to generate an elliptical 3D motion of contact point. The modal shape of the piezoelectric transducer at resonance frequency $93.2 \mathrm{kHz}$ is presented in Figure 5.

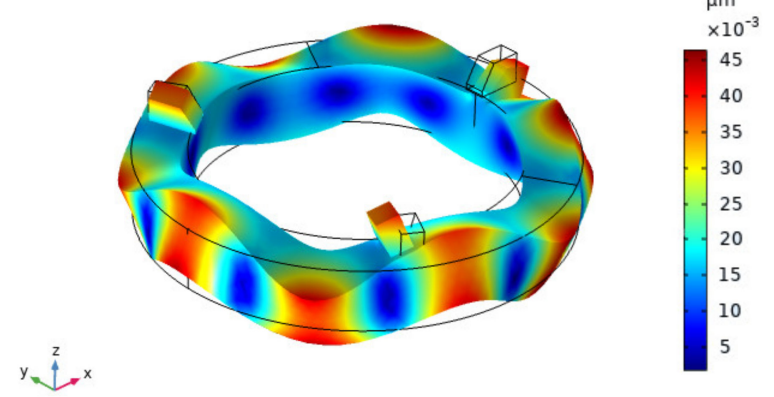

Figure 5. The modal shape of the ring-shaped piezoelectric transducer at a frequency of $93.2 \mathrm{kHz}$.

Lastly, modal shapes of unimorph actuator were analyzed when the disc and triangle-shaped flanges were used. The needed modal shapes were determined at the frequencies of $94.8 \mathrm{kHz}$ and $95.3 \mathrm{kHz}$ for the actuators with a disc and triangle-shaped flanges, as shown in Figure 6. Contact elements are displaced in radial and axial directions; therefore, the contact point moves in the $\mathrm{XZ}$ plane and these modes of vibrations and can be used for rotor driving. 


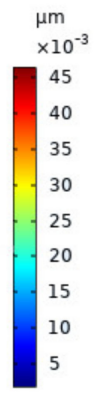
$\stackrel{2}{i}+x$

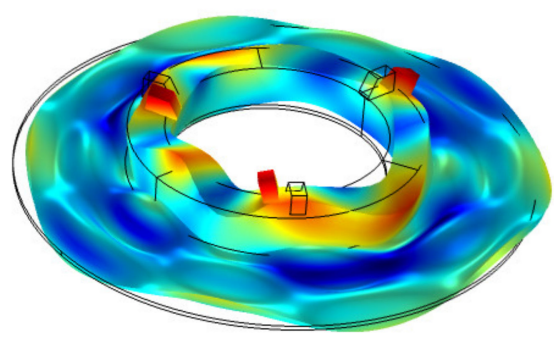

(a)

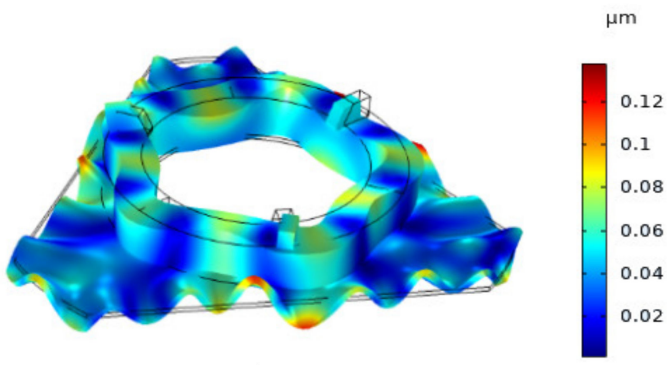

(b)

Figure 6. Modal shapes of vibration of the unimorph actuator: (a) with disc-shaped flange $(94.8 \mathrm{kHz})$; (b) with triangle-shaped flange $(95.3 \mathrm{kHz})$.

Harmonic response analysis of the actuator was performed as well. The aim of numerical simulations were to determinate the rebound of the contact element and find out its trajectory of motion while voltage is applied to one of the segmented electrodes. An amplitude of driven electric signal was $50 \mathrm{~V}$ and this signal was provided for one of the top electrodes while the bottom electrode was grounded. The analysis was performed in a frequency range of $85 \mathrm{kHz}-105 \mathrm{kHz}$, while the solution step was $50 \mathrm{~Hz}$. The piezoelectric actuator has a symmetrical structure. Hence only one segment of the top electrode was excited. Numerical simulation was performed when the actuator had a disc-shaped and triangle-shaped flange, respectively. The displacement amplitudes in $X, Y$, and Z directions were studied and compared. The results of the harmonic response analysis are presented in Figures 7 and 8.

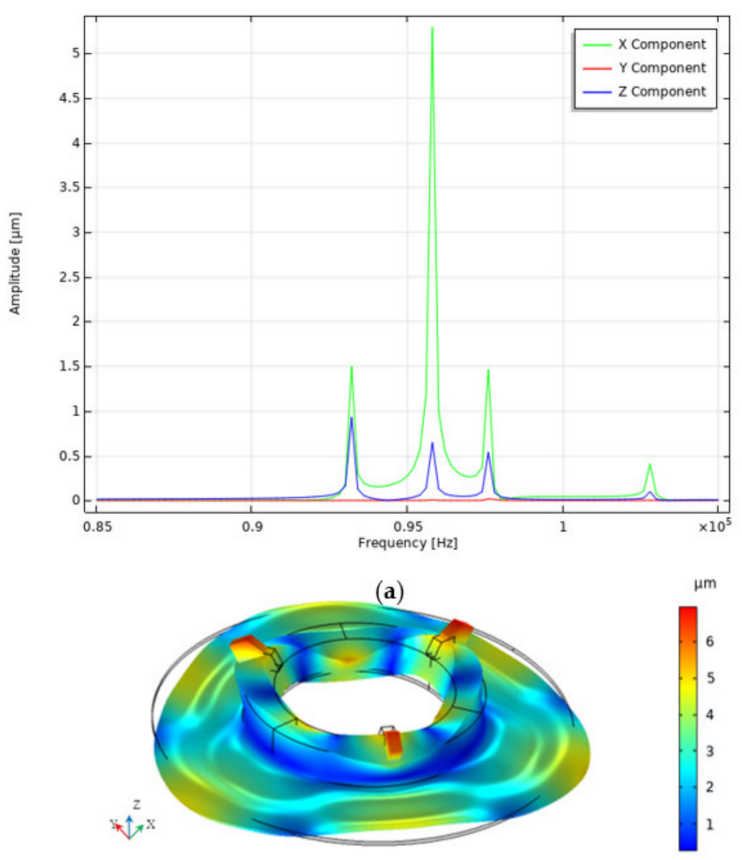

(b)

Figure 7. Results of numerical analysis of harmonic response with the disc-shaped flange: (a) amplitude vs. frequency characteristic; (b) At resonance mode, $95.8 \mathrm{kHz}$. 


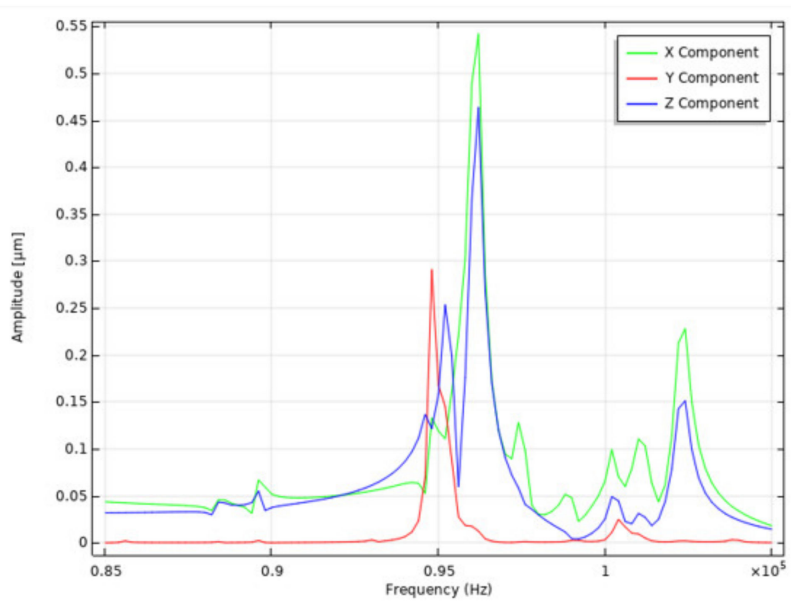

(a)

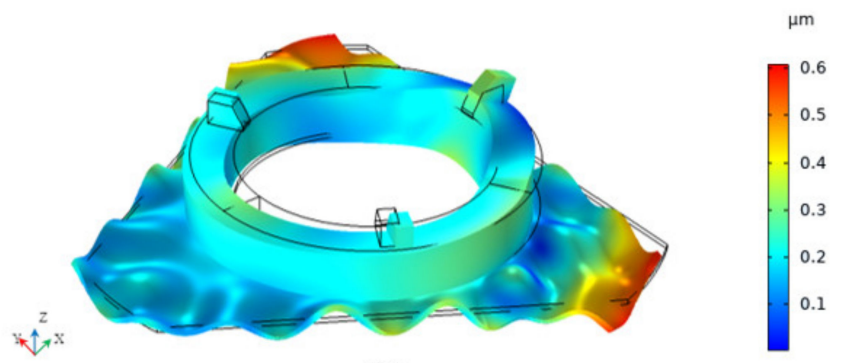

(b)

Figure 8. Results of numerical analysis of harmonic response with the triangle-shaped flange: (a) amplitude vs. frequency characteristic; (b) At resonance mode, $96.2 \mathrm{kHz}$.

A comparison of the displacement amplitudes of the actuator with disc and triangle-shaped flanges are presented in Figure 9.

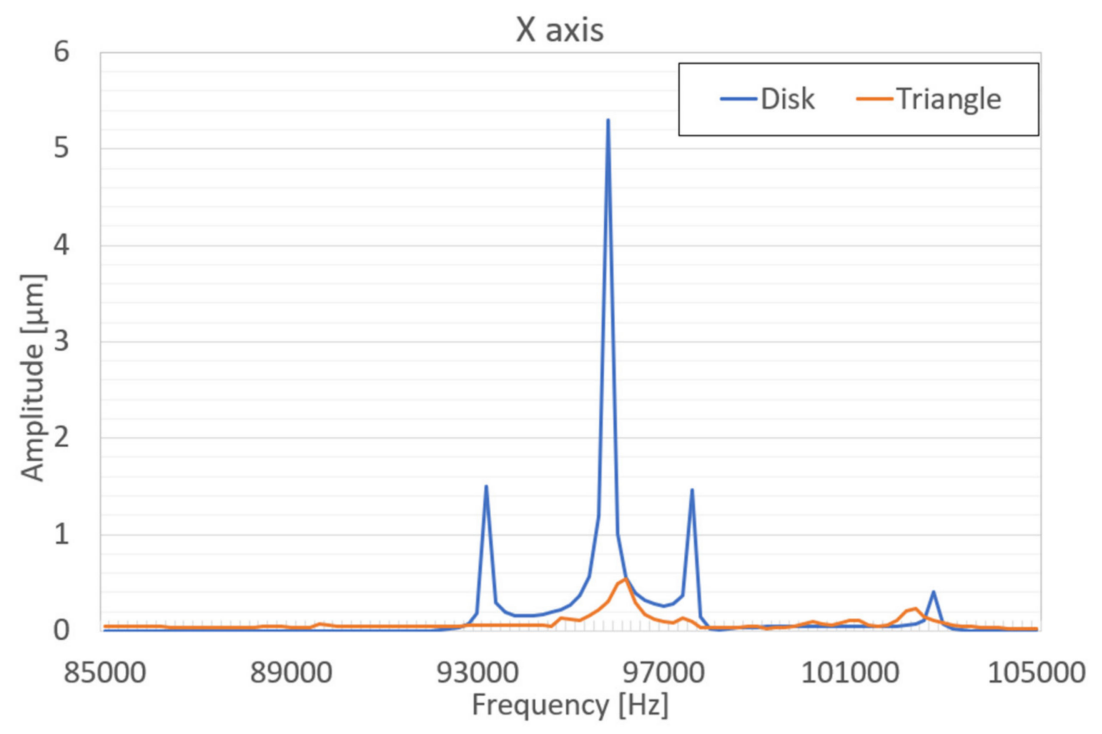

(a)

Figure 9. Cont. 


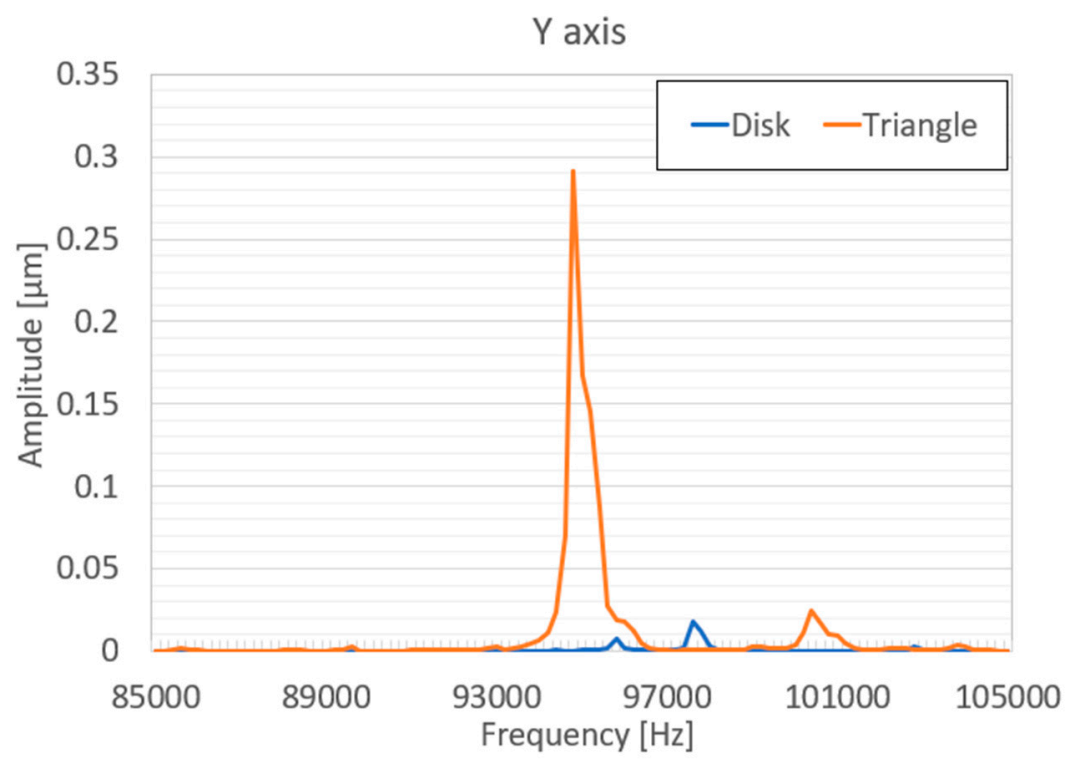

(b)

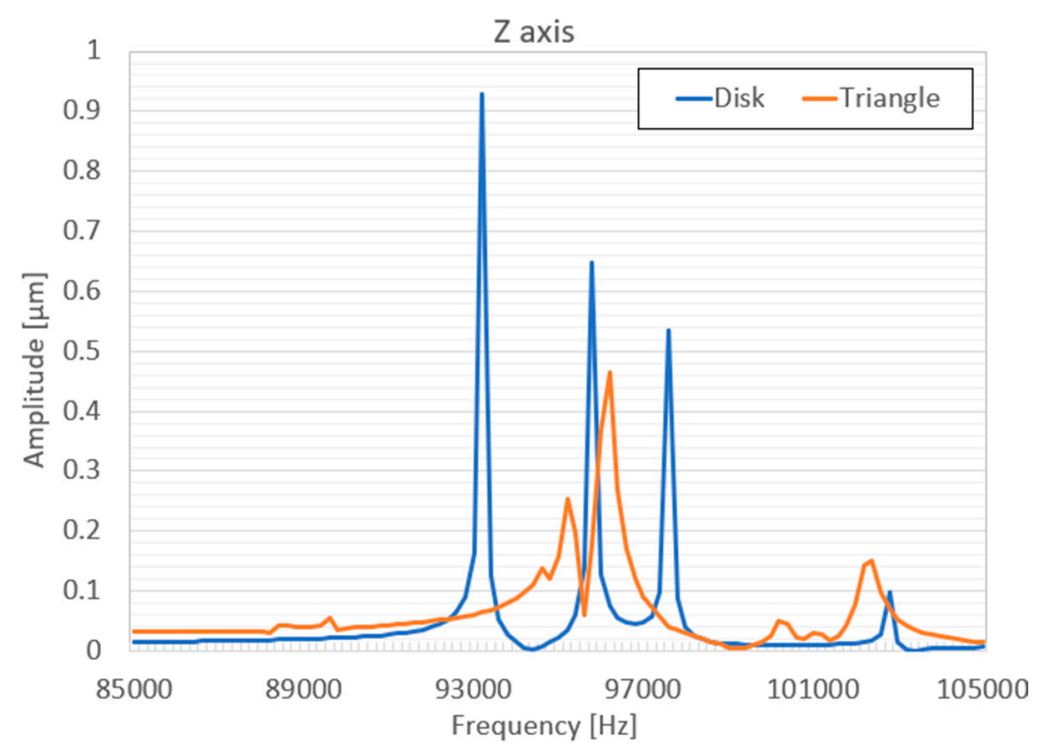

(c)

Figure 9. Comparison of the $X, Y$, and $Z$ displacements versus frequency of actuators with the disc and triangle-shaped flanges: (a) displacements in $\mathrm{x}$-direction; (b) displacements in $\mathrm{y}$-direction; (c) displacements in z-direction.

From the graphs, it can be seen that dominant vibrations appear in radial and axial directions, i.e., $\mathrm{X}$ and $\mathrm{Z}$ accordingly, and the shape of the flange has a big influence on the displacement amplitude. The higher amplitude was determined in the $X$-axis direction for an actuator with a disc-shaped flange. The value of this displacement is $6.2 \mu \mathrm{m}$. Axial displacements in the $Z$-axis direction is also for an actuator with a disc-shaped flange and equal to $0.92 \mu \mathrm{m}$. It must be noted that using a triangle shape for the flange, vibration amplitude is significantly smaller compared with the disc-shaped actuator. The actuator with a disc-shaped flange reaches its resonant peak at $95.8 \mathrm{kHz}$, while the actuator with a triangle-shaped flange at a frequency of $96.2 \mathrm{kHz}$. Amplitudes in $\mathrm{X}$ and $\mathrm{Z}$ directions decrease accordingly with the higher resonant frequencies. 
Contact point (Figure 3) trajectories were calculated in the XZ plane when different flanges of the unimorph actuator were used. Trajectories were analyzed at the vibration frequency of $95.8 \mathrm{kHz}$ and $96.2 \mathrm{kHz}$ for disc-shaped flange triangle-shaped flange, respectively. The results of elliptical movement trajectories are presented in Figure 10. It can be noticed that trajectories are in elliptical shape, but the length of the major and minor axes are different. Lengths of the ellipsis major and minor axes are shown in Table 3. From the results can be seen that the longer length of the ellipsis axis has the actuator with the disc-shaped flange. Results from numerical simulations confirmed that elliptical trajectories could be achieved, and that the proposed actuator can be used for USM.

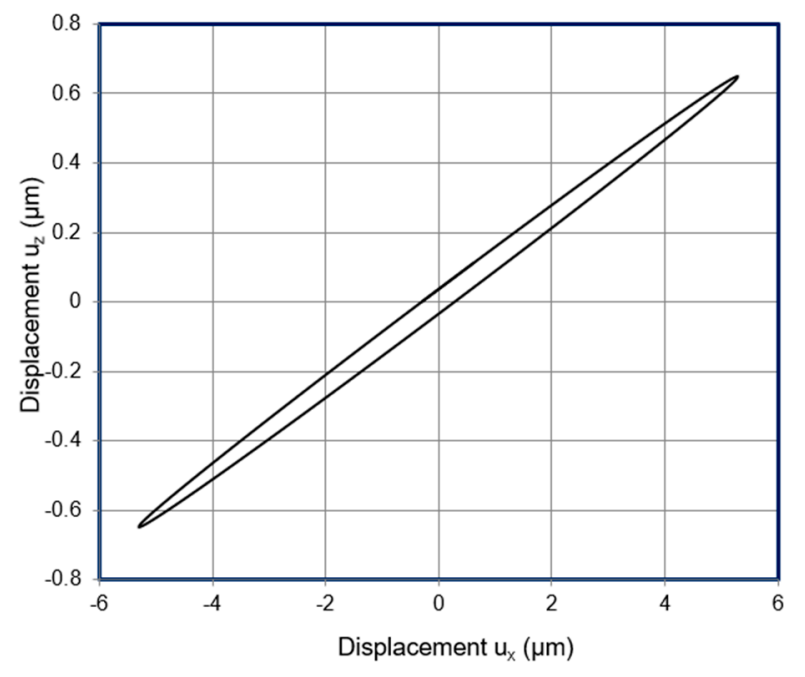

(a)

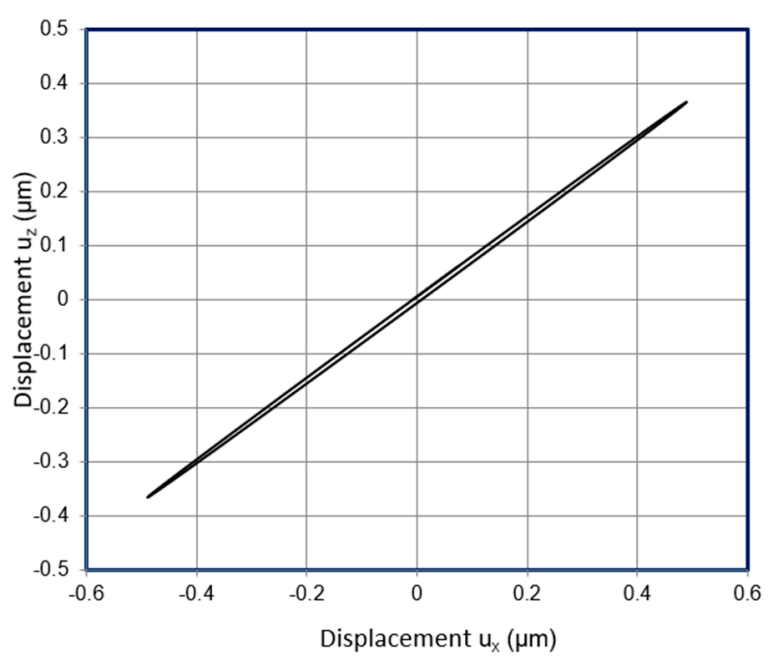

(b)

Figure 10. Motion trajectories of contact point: (a) disc-shaped flange at frequency $95.8 \mathrm{kHz}$; (b) triangle flange at frequency $96.2 \mathrm{kHz}$.

Table 3. Length of major and minor axes, $\mu \mathrm{m}$.

\begin{tabular}{ccc}
\hline Flange & Disc & Triangle \\
\hline Major axis $U_{(x z)}$ & 10.7 & 1.22 \\
Minor axis $U_{(x z)}$ & 3.42 & 0.584 \\
\hline
\end{tabular}




\section{Experimental Studies}

Experimental studies were accomplished. Three experimental prototypes of the piezoelectric actuator were designed and built for the result validation of the numerical study. One prototype was a ring-shaped transducer attached to the soft rubber base. The other two prototypes were of unimorph-type with the disc and triangle-shaped flanges and piezoelectric ring-shaped transducers bonded using epoxy resin. The piezoelectric material of PZT-4 was used for the transducer, the dimensions and properties of the materials are shown in Table 1. Laser scanning vibrometer Polytec PSV-500-3D-HV (Waldbronn, Germany) and driving voltage amplifier P200 (FLC Electronics AB, Partille, Sweden) were used for the experimental studies [21,22]. The experimental setup is presented in Figure 11.

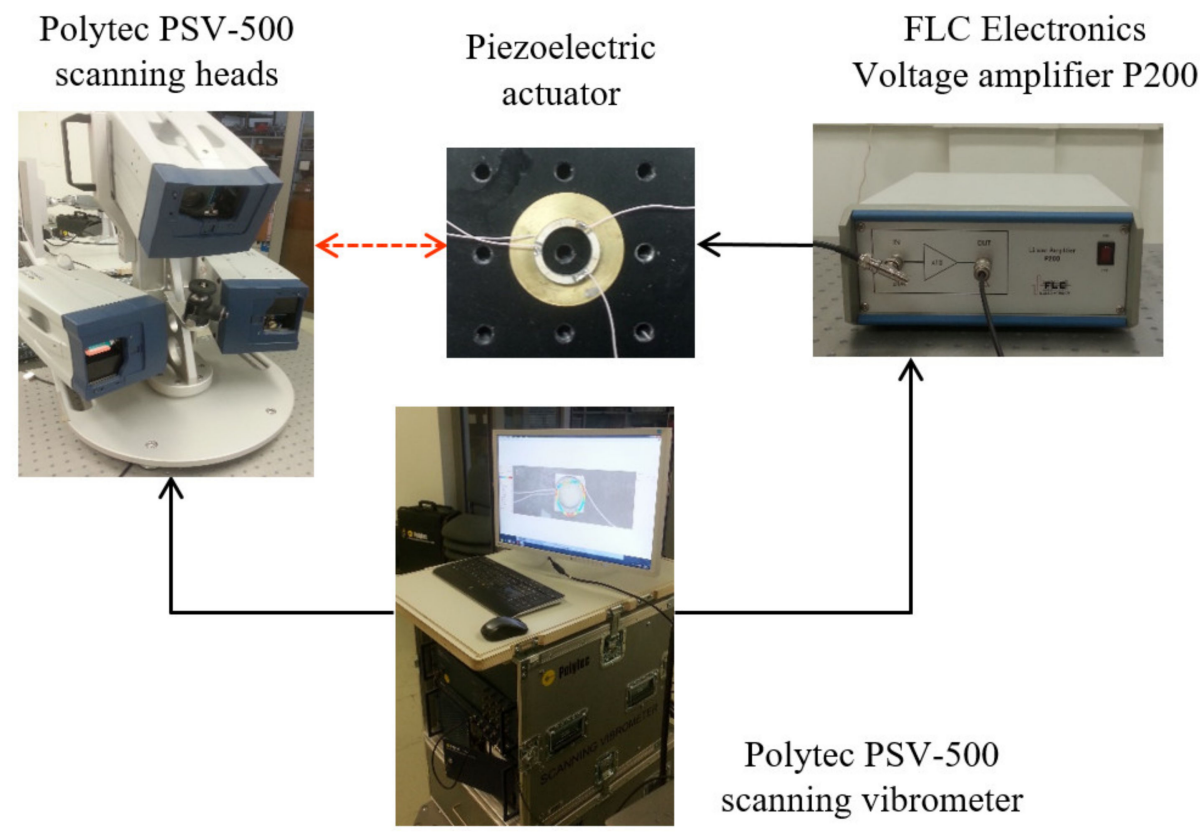

Figure 11. Measurement instruments used in experiments: Polytec Laser Doppler Scanner PSV-500-3D-HV.

An experimental investigation of the dynamic characteristics of the actuators using a Polytec scanner was executed with the following steps: first of all, planar surfaces of the actuators were scanned, and virtual meshes were created. Later, the driven electric signal was determined in a frequency range from 50 to $110 \mathrm{kHz}$. This signal was amplified by a voltage amplifier and applied for one of the segmented electrodes of the transducer. 3D scanning vibrometer allows a non-contact, optical measuring of the amplitudes of vibrations and defines the operational frequencies of the actuators. The deformations of the scanned actuators are shown in Figures 12-14.

Firstly, the piezoelectric transducer without flanges was analyzed. This piezoelectric transducer was glued on soft rubber tape and attached to the steel plate. Soft rubber tape reduces constraints, and piezoelectric transducer can perform closer to its natural frequencies of vibration modes. The setup and vibration mode shape of the piezoelectric transducer is shown in Figure 12.

Secondly, an actuator with triangle-shaped flange was measured. The results of measurements are shown in Figure 13 at the vibration frequency of $93.72 \mathrm{kHz}$. Lastly, an actuator with a disc-shaped flange was analyzed. The results of this analysis show that operational vibration modes are achieved at $94.4 \mathrm{kHz}$. The vibration mode shape of the actuator with the disc-shaped flange and measured amplitude of vibration versus frequency graph are presented in Figure 14. 


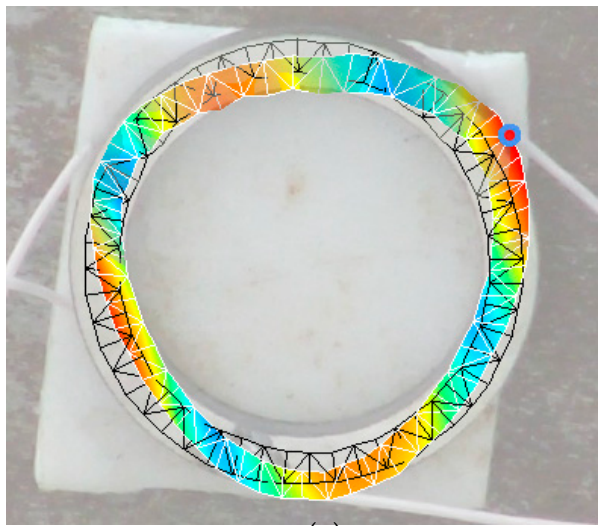

(a)

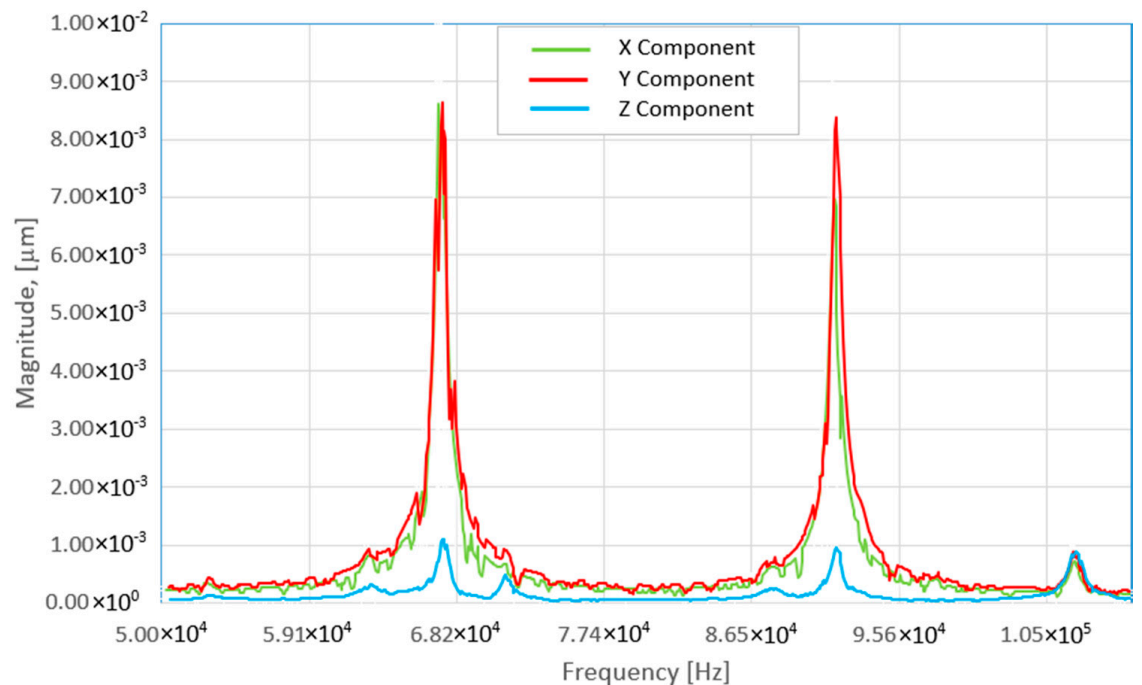

(b)

Figure 12. Measured vibrations of the piezoelectric transducer glued on the soft rubber tape: (a) prototype deformations and shape of the transducer driven with harmonic electric signal of the $92.48 \mathrm{kHz}$; (b) amplitude vs. frequency graph, peaks of oscillations at 61 and $92.48 \mathrm{kHz}$.

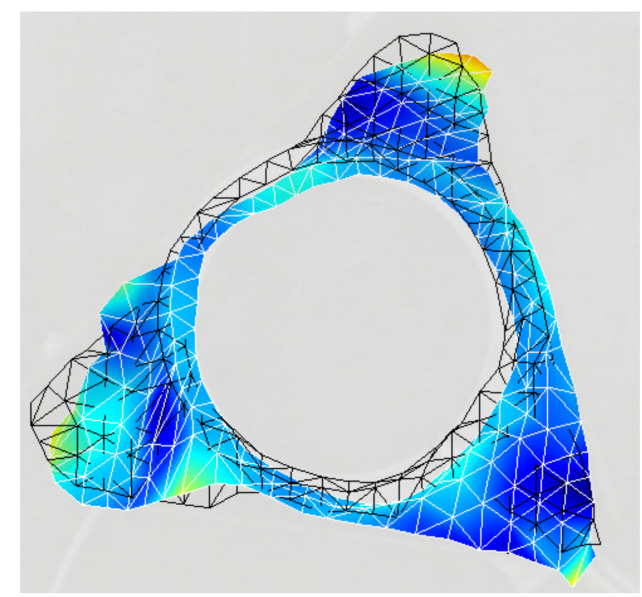

(a)

Figure 13. Cont. 


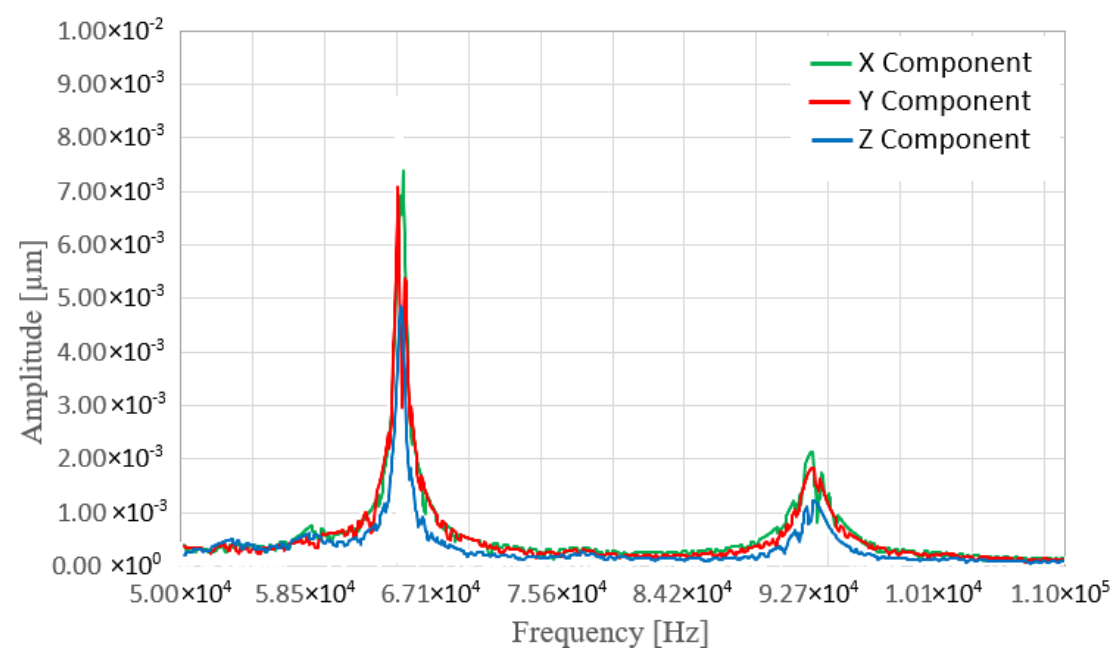

(b)

Figure 13. Measured vibrations of the actuator with triangle-shaped flange: (a) deformations of the actuator with disc-shaped flange at $93.72 \mathrm{kHz}$; (b) amplitude vs. frequency graph, peaks of oscillations at 64.8 and $93.72 \mathrm{kHz}$. Red-X, green-Y, blue-Z coordinates.

It could be noticed that deformations of the actuators are similar to what was achieved in numerical simulations. Displacements in $Z$ direction are relatively small compare to $X$ and $Y$ directions, when piezoelectric transducer operates without flange. When the flange is added, the amplitudes in $\mathrm{Z}$ direction increases and higher displacements are achieved. This is an important feature of the actuator design, and it crucial for the elliptical trajectories' generation of the contact point and proper operation of the actuator. Moreover, it can be noticed that results of displacement amplitudes of numerical calculations are similar to experimental studies, actuator with disc-shaped flange is $\sim 1 \%$ and with triangle-shaped flange $\sim 3 \%$ higher than experimental measurements. The errors can be induced by various causes: slightly different material properties, inaccurate prototypes' dimensions and others. Deformations of actuators and their oscillation modes during experimental studies are more pronounced and visible in excitation zones than numerical calculations. This could be a reason of additional mass of wire soldering points, not free fixtures, errors of measurements.

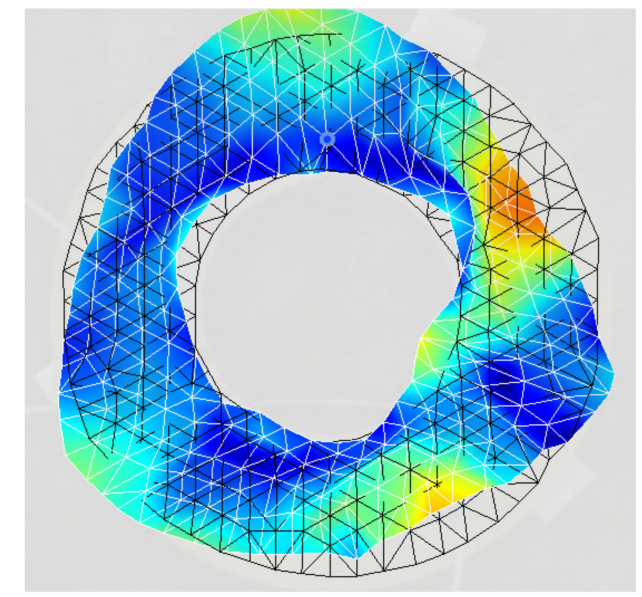

(a)

Figure 14. Cont. 


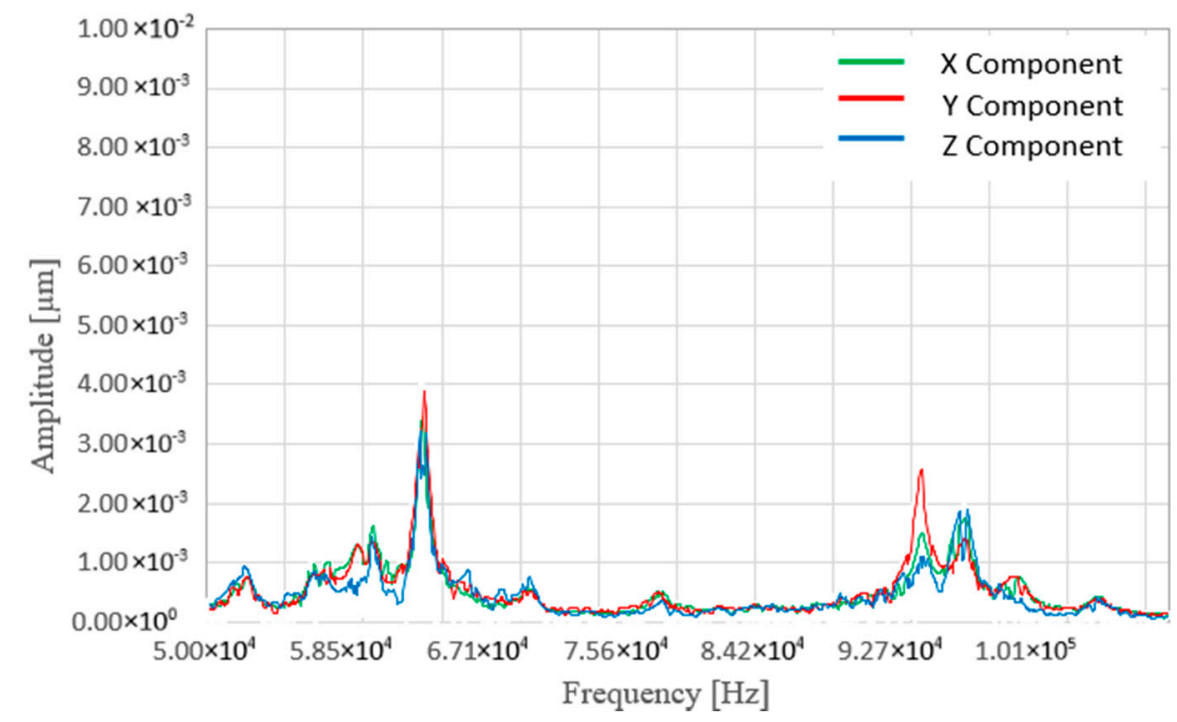

(b)

Figure 14. Measured vibrations of the actuator with disc-shaped flange: (a) deformations of the actuator with disc-shaped flange at $94.4 \mathrm{kHz}$; (b) amplitude vs. frequency graph, peaks of oscillations at 61 and $94.4 \mathrm{kHz}$. Red-X, green-Y, blue-Z coordinates.

Additionally, experiments with the pre-load were performed. Spherical rotor was added and resonance frequencies were measured. During these simulations, resonant frequency was slightly increased and amplitudes slightly reduced. The resonance frequencies (operating frequencies) of the actuators without preload/with preload accordingly are: for disk-shaped configuration is $94.4 \mathrm{kHz} / 94.5 \mathrm{kHz}$ and for triangle shaped configuration $93.7 \mathrm{kHz} / 93.9 \mathrm{kHz}$. Also, the rotation speed of the spherical rotor was measured experimentally. An amplitude of driving electric signal of $70 \mathrm{~V}$ was connected to a one electrode of the 3 segmented electrodes. Rotary speed at operating frequency for a disk-shaped actuator was approximately $30 \mathrm{rpm}$, for a triangle-shaped actuator $27 \mathrm{rpm}$. The preload of the of the sphere was $0.65 \mathrm{~N}$.

\section{Conclusions}

A novel 3DOF piezoelectric USM with a spherical rotor was developed and investigated in this paper. A proposed piezoelectric ultrasonic motor with spherical rotor and two unimorph-type actuators are mainly focused on miniaturization and high-power density. An unimorph actuator combines piezoelectric ring-shaped transducer bonded to a thin bronze flange. Two shapes of the bronze flange were investigated: disc- and triangle-shaped. Numerical simulations and experiments were accomplished, and the working principle of the actuator was validated. Particular modal shapes were determined that can be used for the generation of the 3DOF rotor motion. Results of harmonic response analysis showed that the largest amplitudes of oscillation were achieved when the flange has the disc-shape. Analysis of contact point oscillations trajectories was performed, and it was shown that elliptical trajectories of the contact point motion are generated at operating frequencies and can generate rotary motion of the spherical rotor. Three prototypes of USM were made when a ring-shaped piezoelectric transducer and two unimorph-type piezoelectric actuators with disc-shaped and triangle-shaped flanges were used. Measurement of actuator vibrations confirmed the results of numerical simulation. The difference between the results of measurement and numerical simulations at resonant frequencies are below $\sim 1 \%$ and $\sim 3 \%$ for disc-shaped and triangle shaped flanges, accordingly. Some decrease of an amplitude and shift of the resonance frequency of the unimorph actuators was determined using a preload (weight of the spherical rotor). The resonance frequencies (operating frequencies) of the actuators without preload/with preload, accordingly, are: for disk-shaped 
configuration $94.4 \mathrm{kHz} / 94.5 \mathrm{kHz}$ and for triangle shaped configuration $93.7 \mathrm{kHz} / 93.9 \mathrm{kHz}$. The rotary speed of the rotor at an operating frequency and amplitude of driving electric signal of $70 \mathrm{~V}$ for a disk-shaped actuator was approximately $30 \mathrm{rpm}$, for a triangle-shaped actuator $27 \mathrm{rpm}$.

Author Contributions: V.J. was responsible for conceptualization, creation of experimental investigations and methodology, reviewing and editing the manuscript. G.K. contributed to numerical and experimental investigations, writing and preparation of the manuscript. D.M. contributed to formal analysis, writing and editing of the manuscript. All authors have read and agreed to the published version of the manuscript.

Funding: This research was funded by the European Regional Development Fund under a grant agreement with the Research Council of Lithuania, grant number 01.2.2-LMT-K-718-01-0010.

Acknowledgments: This project has received funding from the European Regional Development Fund (project according to the supported activity No. 01.2.2-LMT-K-718-01-0010) under a grant agreement with the Research Council of Lithuania.

Conflicts of Interest: The authors declare no conflict of interest.

\section{References}

1. Kang, B.; Lee, J.; Won, C. Micro-navigation satellite network design and analysis. In Proceedings of the 21st International Technical Meeting of the Satellite Division of The Institute of Navigation, Savannah, GA, USA, 16-19 September 2008; pp. 867-876.

2. Uchino, J.; Giniewicz, J.R. MicroMechatronics; Marcel Dekker Inc.: New York, NY, USA, 2003; pp. 1-32.

3. Mazeika, D.; Vasiljev, P.; Bareikis, R.; Borodinas, S. 3DOF high resolution inertial piezoelectric motor. In Proceedings of the International Ultrasonics Simposium, Glasgow, UK, 6-9 October 2019; pp. 1773-1776.

4. Bansevicius, R.; Bagdoniene, J.; Jurenas, V.; Kulvietis, G.; Mazeika, D.; Drukteiniene, A. Single cylinder-type piezoelectric actuator with two active kinematic pairs. Micromachines 2018, 9, 597. [CrossRef]

5. Hassani, V.; Tjahjowidodo, T. Dynamic modeling of 3-DOF pyramidal-shaped piezo-driven mechanism. Mech. Mach. Theory 2013, 70, 225-245. [CrossRef]

6. Chatttaraj, N.; Ganguli, R. Electromechanical analysis of piezoelectric bimorph actuator in static state considering the nonlinearity at high electric field. Mech. Adv. Mater. Struct. 2015, 23, 1-16.

7. Vasiljev, P.; Mažeika, D.; Kulvietis, G.; Vaičiulienè, S. Piezoelectric actuator generating 3D-rotations of the sphere. Solid State Phenom. 2006, 113, 173-178. [CrossRef]

8. Li, Z.; Guo, P.; Wang, Z.; Zhao, L.; Wang, Q. Design and analysis of electromagnetic-piezoelectric hybrid driven three-degree-of-freedom motor. Sensors 2020, 20, 1621. [CrossRef] [PubMed]

9. Keller, B.; Schinkoethe, W.; Bastian, K.; Schinkoethe, W. Multi-degree-of-freedom. In Jahresberichr IKFF 2013; IKFF: Stuttgart, Germany, 2013.

10. Lu, B.; Aoyagi, M.; Takano, T.; Tamura, H. Examination of sandwich-type multidegree-of-freedom spherical ultrasonic motor. Jpn. J. Appl. Phys. 2010, 49, 1-7. [CrossRef]

11. Jūrènas, V.; Kazokaitis, G.; Mažeika, D. 3DOF ultrasonic motor with two piezoelectric rings. Sensors 2020, 20, 834. [CrossRef] [PubMed]

12. Bansevičius, R.; Mažeika, D.; Jūrẻnas, V.; Kulvietis, G.; Drukteiniene, A. Multi-DOF ultrasonic actuators for laser beam positioning. Shock Vibr. 2019, 2019, 1-13. [CrossRef]

13. Zhao, C. Ultrasonic motors. In Technologies and Applications; Science press: Beijing, China, 2010; pp. 23-27, ISBN 978-7-03-029018-9.

14. DeAngelis, D.A.; Schulze, G.W. Performance of PZT8 versus PZT4 piezoceramic materials in ultrasonic transducers. Phys. Procedia 2016, 87, 85-92.

15. Zhang, M.; Zhao, J. Electromechanical properties of lead zirconate titanate piezoceramics under the influence of mechanical stresses. IEEE Trans. Ultraso. Ferroelectr. Freq. Control 1999, 46, 1518-1526. [CrossRef] [PubMed]

16. Material: Phosphor bronze C52100. Available online: https://www.azom.com/article.aspx?ArticleID=6417 (accessed on 25 March 2020).

17. Material: Lead Zirconate Titanate (PZT). Available online: https://www.memsnet.org/material/ leadzirconatetitanatepzt/ (accessed on 25 March 2020).

18. Piezoceramic Material Data: PZT-4, Lead Zirconate Titatnate. Available online: http://www.efunda.com/ materials/piezo/material_data/matdata_output.cfm?Material_ID=PZT-4 (accessed on 25 March 2020). 
19. Alumina-Aluminum Oxide-Al2O3 -A Refractory Ceramic Oxide. Available online: https://www.azom. com/properties.aspx?ArticleID=52 (accessed on 25 March 2020).

20. Tzou, H.S. Piezoelectric Shells-Distributed Sensing and Control of Continua; Springer: Amsterdam, The Netherlands, 1993; p. 320.

21. PSV-500-3D Scanning Vibrometer. Available online: https://www.polytec.com/fileadmin/d/Vibrometrie/OM_ DS_PSV-500-3D_E_42447.pdf (accessed on 11 December 2019).

22. Piezo Linear Amplifier EPA-104. Available online: https://piezo.com/products/piezo-linear-amplifier (accessed on 11 December 2019). 